\title{
Photocatalytic degradation of aqueous organic solvents in the presence of hydroxyl radical scavengers
}

\author{
Mehrab Mehrvar, ${ }^{1, \dagger}$ William A. Anderson, ${ }^{2}$ and Murray Moo-Young ${ }^{2}$ \\ ${ }^{1}$ Department of Chemistry, Biology and Chemical Engineering, Ryerson Polytechnic University, \\ Toronto, Ontario, Canada M5B 2K3 \\ ${ }^{2}$ Department of Chemical Engineering, University of Waterloo, Waterloo, Ontario, Canada N2L 3G1
}

\begin{abstract}
Tetrahydrofuran (THF) and 1,4-dioxane (DIOX) are two common solvents that are found in contaminated groundwater. Photocatalytic degradation of these two organic solvents in water was studied in the presence of carbonate and bicarbonate, which are hydroxyl radical scavengers. The reactions were performed in an annular slurry photoreactor. It was found that bicarbonate and carbonate ions acted as hydroxyl radical scavengers and slowed down the DIOX degradation rate but did not significantly affect the THF degradation rate. The slight enhancement in the THF degradation rate in the presence of sodium bicarbonate may be due to the increase in $\mathrm{pH}$. In addition, it appears that bicarbonate and carbonate ions were reduced to other organic species during the photocatalytic reaction.
\end{abstract}

\section{INTRODUCTION}

The presence of some inorganic impurities may affect the photocatalytic destruction of organics in water and wastewater. It is believed that these anions scavenge hydroxyl radicals [4, 6-10], which are responsible for attacking organics. To date there is little information regarding the effects of these impurities on photocatalysis. Although there are some studies which include the effects of these ions in advanced oxidation processes (AOPs) [4, 6-10], these effects are sometimes neglected in photocatalysis. Bicarbonate and carbonate ions are commonly found in surface waters, groundwaters, and wastewaters. For instance, bicarbonate ions in the Gloucester landfill groundwater, Gloucester, Ontario, Canada, are about 150-300 mg/L ( 2.5-5 mM) [11]. In the previous study [18], the photocatalytic degradation of THF and DIOX was thoroughly investigated in the absence of carbonate and bicarbonate scavengers. In this study, the effects of these ions on the photocatalytic degradation of tetrahydrofuran and 1,4-dioxane were examined. For the purpose of this investigation, $\mathrm{NaHCO}_{3}$ was used to explore the effects of carbonate and bicarbonate anions on the photocatalytic degradation of THF and DIOX.

Most water and wastewater samples will have a few inorganic compounds that can potentially act as hydroxyl radical scavengers during photocatalysis processes. Carbonate and bicarbonate ions are well known as hydroxyl radical scavengers in processes such as flash photolysis and pulse radiolysis [1-5, 10]. Other anion species such as phosphates, sulfates, and nitrates may also be present in water and their effects on photocatalysis need to be addressed. Behar et al. [4] and other researchers $[1-3,5,10]$ showed that in pulse radiolysis,

\footnotetext{
† E-mail: mmehrvar@ryerson.ca
}

bicarbonate and carbonate ions react with hydroxyl radicals to produce carbonate radical ions via the following reactions:

At low pH levels:

$$
\mathrm{HCO}_{3}^{-}+{ }^{\bullet} \mathrm{OH} \rightarrow \mathrm{CO}_{3}^{-\bullet}+\mathrm{H}_{2} \mathrm{O}
$$

and at high $\mathrm{pH}$ levels:

$$
\mathrm{CO}_{3}^{2-}+{ }^{\bullet} \mathrm{OH} \longrightarrow \mathrm{CO}_{3}^{-\bullet}+\mathrm{OH}^{-} .
$$

Although the exact mechanism of the formation of these carbonate radicals is not clear, Weeks and Rabani [10] demonstrated that the decay of these carbonate radical ions might occur through the following reactions:

$$
\mathrm{CO}_{3}^{-\bullet}+\mathrm{CO}_{3}^{-\bullet} \longrightarrow \mathrm{CO}_{2}+\mathrm{CO}_{4}^{-2}
$$

or

$$
\mathrm{CO}_{3}^{-\bullet}+\mathrm{CO}_{3}^{-\bullet}+\mathrm{H}_{2} \mathrm{O} \longrightarrow 2 \mathrm{CO}_{2}+\mathrm{HO}_{2}^{-}+\mathrm{OH}^{-} .
$$

\section{EXPERIMENTAL PROCEDURE}

An experimental set up was made of an annular photoreactor with a glass cylinder of $105 \mathrm{~mm}$ internal diameter (ID) and a concentric internal glass cylinder of $48 \mathrm{~mm}$ outer diameter and $44 \mathrm{~mm}$ inner diameter. Both cylinders were made of borosilicate glass with a height of $60 \mathrm{~cm}$. The liquid was recirculated through the reservoir to the photoreactor using a $1 / 3 \mathrm{hp}$-magnetic drive pump with 3450 rpm (Fluids Control Division, Hamden, Connecticut, USA). The temperature throughout the experiments was kept at $25 \pm 2{ }^{\circ} \mathrm{C}$ with a circulating water bath (NESLAB RTE 111). Six low-pressure mercuryvapor fluorescent UV lamps around the photoreactor 


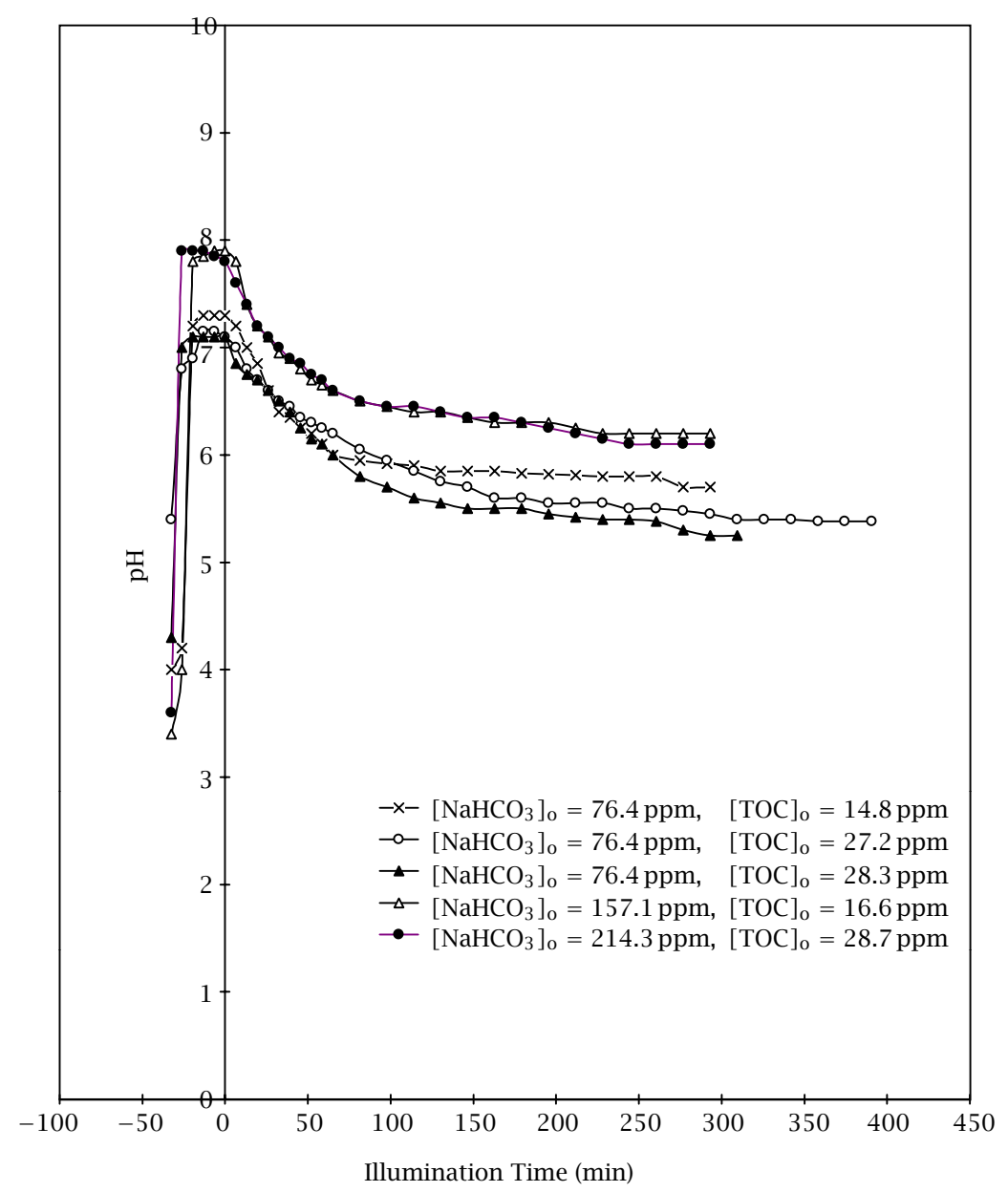

Figure 1. pH profile for the photocatalytic degradation of the binary system (THF and DIOX) in the presence of $\mathrm{NaHCO}_{3}$ in the slurry photoreactor.

and one inside the inner cylinder provided light. The liquid in the reservoir was magnetically stirred to increase the mass transfer between the headspace and the liquid as well to provide enough oxygen transfer to the liquid. Filtered deionized water was used in all experimental trials. The system was loaded with filtered deionized water and aerated for half an hour prior to each run. During this time, the UV lights were on in order to destroy any background trace of organics possibly left in the system. Then, a certain amount of stock solution of the pollutant, in this case 1,4-dioxane and tetrahydrofuran, was injected into the system while the lights were off. The liquid was then allowed to recirculate for a couple of hours to reach equilibrium. The reaction was started by switching on the lights. Periodically, samples were withdrawn from the mid-section of the photoreactor and analyzed by a Hewlett Packard (Avondale, PA) 5890 Series II gas chromatograph which was equipped with a flame ionization detector (FID). The column was an RTX-502.2 fused Silica megabore column with $30 \mathrm{~m} \times 0.53 \mathrm{~mm}$ ID and $3.0 \mu \mathrm{m}$ film thickness
(Chromatographic Specialties Inc.). The samples were collected in the small $2 \mathrm{~mL}$ vials capped with Teflon face septa (Chromatographic Specialties Inc.). The catalyst loading was optimized by a series of titanium dioxide loading experiments and it was found that the optimum catalyst loading is $1.5 \mathrm{~g} / \mathrm{L}$.

\section{RESULTS AND DISCUSSIONS}

In order to study the effects of carbonate and bicarbonate anions on the photocatalytic degradation of the mixture of THF and DIOX, a few runs with different initial concentrations of sodium bicarbonate (BDH grade) were performed. Figure 1 depicts the $\mathrm{pH}$ changes during the trials. In the $\mathrm{pH}$ range of 5.5-8, both bicarbonate and carbonate anions are present with bicarbonate ions predominating. Hence, Reaction (1) most likely occurs in this range of pH. Figures 2 and 3 compare two identical runs with different initial $\mathrm{NaHCO}_{3}$ concentrations. It was expected that bicarbonate ions scavenge hydroxyl radicals and reduce the degradation rate of 


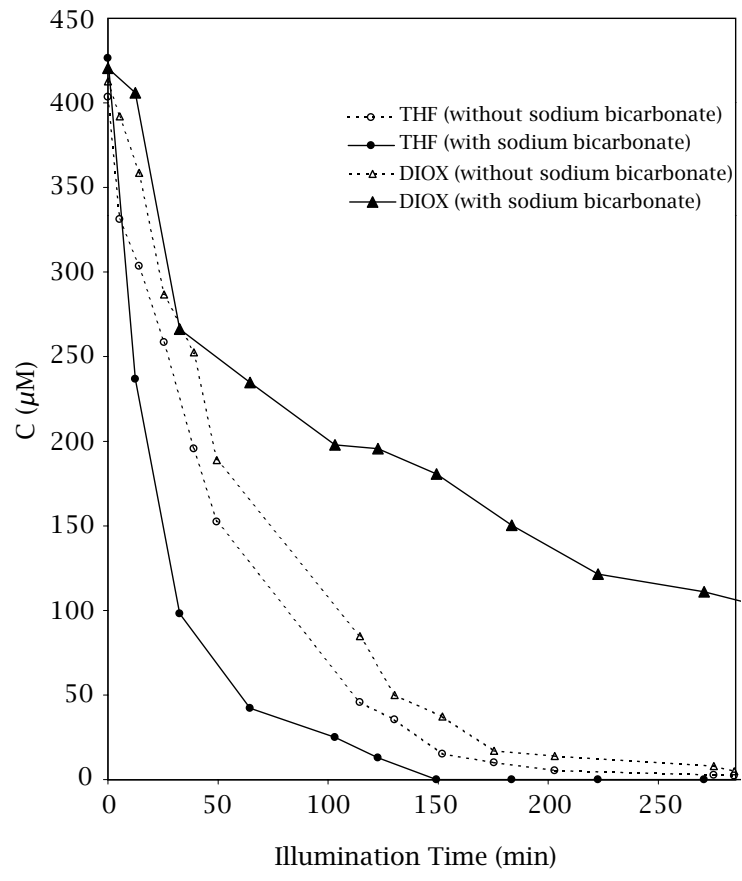

Figure 2. Effect of sodium bicarbonate on the photocatalytic degradation of the binary system (THF and DIOX) in the slurry photoreactor, for the run with sodium bicarbonate: $\left[\mathrm{NaHCO}_{3}\right]=76.43 \mathrm{mg} / \mathrm{L}$.

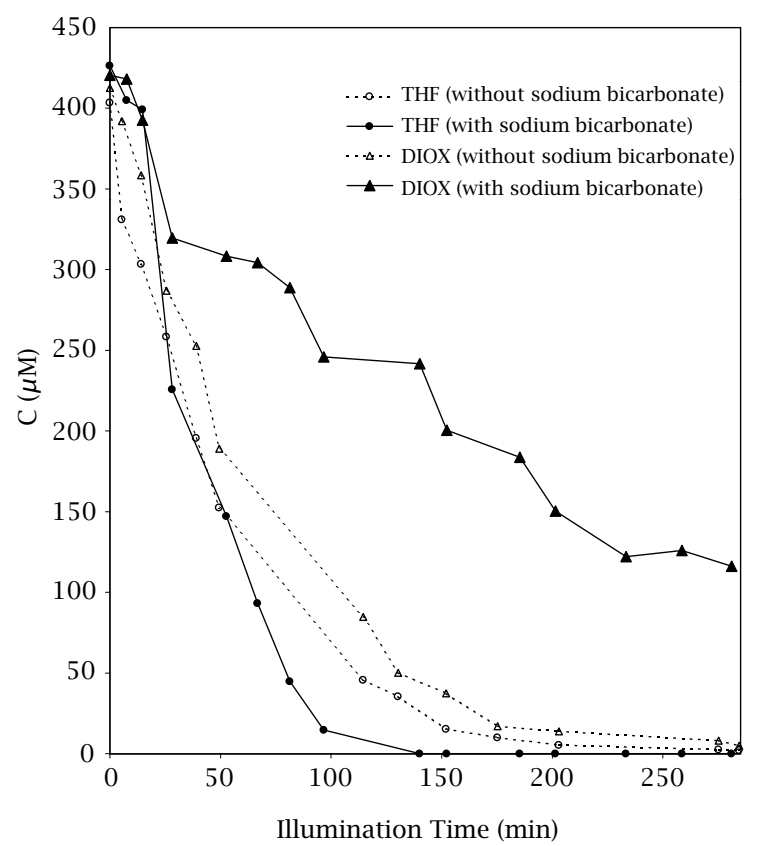

Figure 3. Effect of sodium bicarbonate on the photocatalytic degradation of the binary system (THF and DIOX) in the slurry photoreactor, for the run with sodium bicarbonate: $\left[\mathrm{NaHCO}_{3}\right]=214.29 \mathrm{mg} / \mathrm{L}$. both THF and DIOX. In contrast, Figures 2 and Figure 3 show that the degradation rate of THF was slightly enhanced with increasing $\mathrm{NaHCO}_{3}$ concentration while the degradation rate of DIOX decreased. The slight increase in THF degradation rate may be due to the increase in $\mathrm{pH}$. The $\mathrm{pH}$ change in the binary runs without sodium bicarbonate was 3.5-4.5 as shown in Figure 1 before time zero. The $\mathrm{pH}$ changes for the two binary runs in the presence of sodium bicarbonate were in the ranges of $5.5-7\left(\left[\mathrm{NaHCO}_{3}\right]=76.4 \mathrm{mg} / \mathrm{L}\right)$ and 6.5-8 $\left(\left[\mathrm{NaHCO}_{3}\right]=214 \mathrm{mg} / \mathrm{L}\right)$, respectively.

Ortyl and Peck [12] demonstrated that both organic adsorption and particle suspension depend on the $\mathrm{pH}$ of the suspension and the point of zero charge (PZC) of titanium dioxide. PZC determines the charge characteristics of the solid surface, which is the $\mathrm{pH}$ at which the net surface charge is zero. The net surface charge is positive below the PZC and negative above the PZC. During sampling from the reactor in the presence of sodium bicarbonate, it was observed that the titanium dioxide particles settled down in the vials completely after a few minutes. On the other hand, the particles did not precipitate after hours in the samples taken from the runs without sodium bicarbonate. This observation indicates that the PZC of titanium dioxide was within the working $\mathrm{pH}$ range of the runs with sodium bicarbonate, i.e., $\mathrm{pH}$ of 5.5-8. The net surface charge of the particles becomes zero at PZC and therefore, the particles settle down easily.

Ortyl and Peck [12] found that the PZC of titanium dioxide containing anatase and rutile with $0.03 \mu \mathrm{m}$ particle size is 6.83 . Therefore, it seems that at a $\mathrm{pH}$ below the PZC, the THF degradation rate is enhanced (Figure 2). On the other hand, by almost tripling the $\mathrm{NaHCO}_{3}$ concentration to $214 \mathrm{mg} / \mathrm{L}$ and elevating the $\mathrm{pH}$ above the PZC, the THF degradation rate was not significantly different from that without $\mathrm{NaHCO}_{3}$. This suggests that the degradation of THF is enhanced within the $\mathrm{pH}$ range of 5.5-7, whereas it did not show a significant change at higher $\mathrm{pH}$ levels. It is also possible that within the $\mathrm{pH}$ range of 5.5-7, THF adsorption was greater than that at $\mathrm{pH}$ levels above the PZC.

Although the decrease of DIOX degradation rate may be due to the shortage of hydroxyl radicals, it is possible that the DIOX degradation is favored by lower $\mathrm{pH}$ conditions. Therefore, there are two factors that may play important roles in describing the degradation changes in the presence of sodium bicarbonate. These factors are:

- Scavenging hydroxyl radicals by bicarbonate and carbonate ions.

- pH changes.

Figure 4 shows a typical carbon balance profile in the photocatalytic degradation of THF and DIOX in the presence of sodium bicarbonate. This figure depicts 


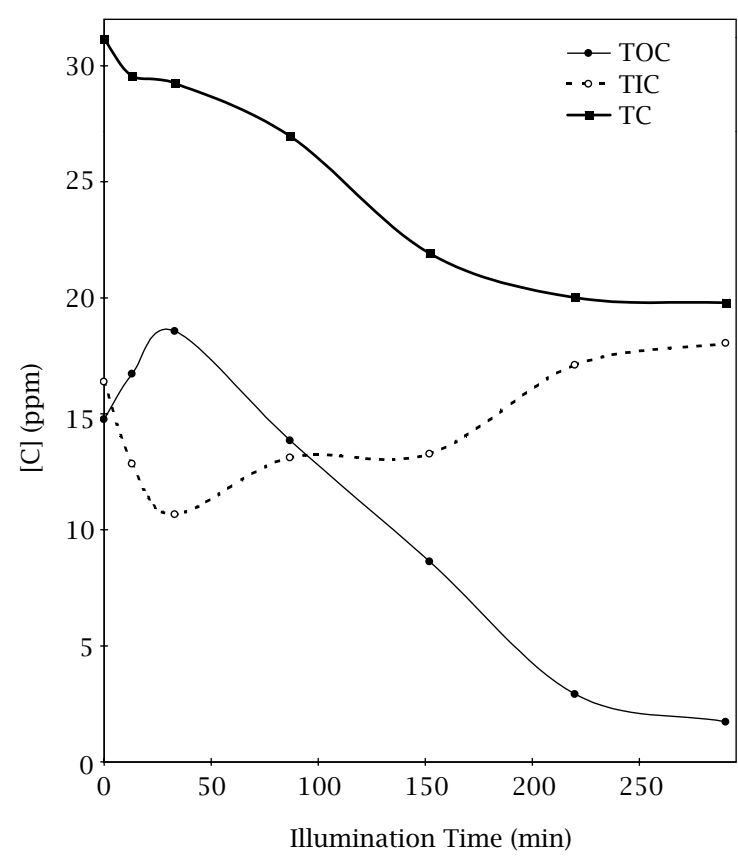

Figure 4. A typical carbon balance profile for the photocatalytic degradation of the binary system (THF and DIOX) in the presence of sodium bicarbonate, $\left[\mathrm{NaHCO}_{3}\right]=$ $76.43 \mathrm{mg} / \mathrm{L}$.

that during the initial part of the reaction, the TOC increases for the first 50 minutes of the illumination time and then decreases. At the same time, the TIC decreases in the initial part of the reaction and then increases. The TOC increase in the initial part of the reaction may be due to the desorption of organic species from the catalyst surface into the liquid phase. Alternatively, it is also possible that some carbonate and bicarbonate ions convert to organics that could also explain the initial increase in TOC. Previous studies support this observation. Chandrasekaran and Thomas [13] and Monheit et al. [14] showed that carbonate ions could be photochemically reduced to formaldehyde. Also, Khalil et al. [15] showed that it is likely that photocatalytically produced electrons reduce carbonate ions initially to formate, $\mathrm{HCOO}^{-}$, and then to formaldehyde, $\mathrm{HCHO}$, and methanol, $\mathrm{CH}_{3} \mathrm{OH}$. In addition, Aurian-Blajeni et al. [16] and Inoue et al. [17] demonstrated that $\mathrm{CO}_{2}$ might be photocatalytically reduced to organic species such as formaldehyde and methanol over semiconductor materials. The dramatic decrease in $\mathrm{pH}$ during the initial stages of the reaction may indicate that bicarbonate and carbonate ions are scavenged by hydroxyl radicals and also reduced to organic species (see Figure 1). The increase in TIC in the second part of the reduction may be a result of $\mathrm{CO}_{2}$ formation. As shown in Figure 4, a slight decrease in the total carbon (TC) may be due to the fact that some $\mathrm{CO}_{2}$ formed during the photocatalytic process releases into the headspace. It is also possible that some of the organics and carbon dioxide produced escape from the reactor through the punctured septa.

To verify the reduction of carbonate and bicarbonate ions to organic species, a run with $214 \mathrm{mg} / \mathrm{L} \mathrm{NaHCO}_{3}$ in the absence of organics was performed. The results of this run are illustrated in Figure 5. The total inorganic carbon decreased dramatically in the first few minutes of the run while at the same time a slight amount of organic carbon was produced. Although the amount of total organic carbon produced was very low, it is possible that the organics degraded immediately after their formation. The high degradation rate of organics produced could be easily explained by the abundance of active sites available in the system and the low concentrations of organics formed. This results in a high active site to reactant species ratio, a condition that favors a rapid reaction.

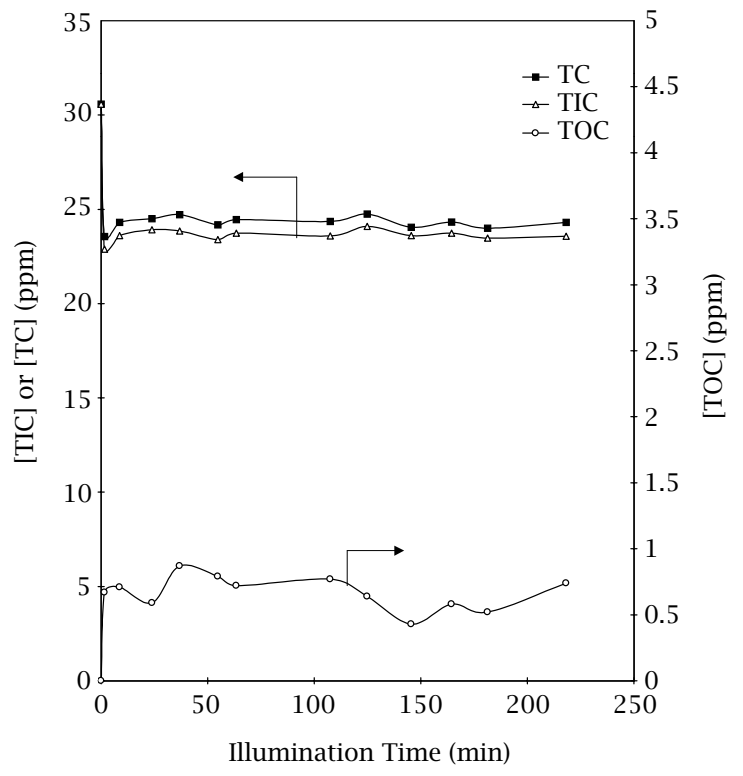

Figure 5. Effects of Photocatalysis on $\mathrm{NaHCO}_{3}$ in the absence of organics; $\left[\mathrm{NaHCO}_{3}\right]=214.29 \mathrm{mg} / \mathrm{L}$.

\section{CONCLUSIONS}

It was shown that the presence of bicarbonate and carbonate ions as hydroxyl radical scavengers slows down the degradation rate of 1,4-dioxane but does not significantly alter the degradation rate of tetrahydrofuran. The slight enhancement in the tetrahydrofuran degradation rate in the presence of sodium bicarbonate may be due to an increase in $\mathrm{pH}$. Also, there is a possibility that bicarbonate and carbonate ions reduce to other organic species during the photocatalytic reaction. Therefore, in photocatalytic processes, the presence of these 
anions should be taken into account. It is recommended that these anions be removed from the water or wastewater before the photocatalysis process is activated in order to eliminate their effects. Lowering the $\mathrm{pH}$ of the water or wastewater before photocatalytic treatment eliminates these anions in the form of $\mathrm{CO}_{2}$.

\section{ACKNOWLEDGEMENTS}

The support of Natural Sciences and Engineering Research Council of Canada is gratefully acknowledged.

\section{References}

[1] G. E. Adams and J. W. Boag, Proceedings of the Chemical Society, London, 1964, p. 112.

[2] G. E. Adams, J. W. Boag, and B. D. Michael, Trans. Faraday Soc. 61 (2) (1965), 1674.

[3] G. E. Adams, J. W. Boag, and B. D. Michael, Trans. Faraday Soc. 61 (2) (1965), 1417.

[4] D. Behar, G. Czapski, and I. Duchovny, J. Phys. Chem. 74 (10) (1970), 2206.

[5] S. Gordon, E. J. Hart, M. S. Matheson, J. Rabani, and J. K. Thomas, J. Amer. Chem. Soc. 85 (2) (1963), 1375.

[6] W. H. Glaze and J.-W. Kang, Ind. Eng. Chem. Res. 28 (1989), 1573.

[7] W. H. Glaze and J.-W. Kang, Ind. Eng. Chem. Res. 28 (1989), 1580.
[8] J. Kochany and E. Lipczynska-Kochany, Chemosphere 25 (12) (1992), 1769.

[9] C. Sundby, FEBS Letters 274 (1/2) (1990), 77.

[10] J. L. Weeks and J. Rabani, J. Phys. Chem. 70 (7) (1966), 2100.

[11] C. Moralejo, Proceeding of The First International Conference on Advanced Oxidation Technology for Water and Air Remediation, London Convention Center, London, Ontario, Canada, June 25-30, 1994.

[12] T. T. Ortyl and G. E. Peck, Drug Development and Industrial Pharmacy 17 (17) (1991), 2245.

[13] K. Chandrasekaran and J. K. Thomas, Chem. Phys. Let. 99 (1983), 7.

[14] D. Monheit, S. Grayer, N. Godinger, V. Katzir, and M. Halmann, Abstract of 5th International Conference on Photochemical Conversion and Storage of Solar Energy, Osaka, 1984, pp. 75-76.

[15] L. B. Khalil, N. S. Youssef, M. W. Rophael, and M. M. Moawad, J. Chem. Tech. Biotechnol. 55 (1992), 391.

[16] B. Aurian-Blajeni, M. Halmann, and J. Manassen, Sol. Energy 25 (1980), 165.

[17] T. Inoue, A. Fujishima, S. Konishi, and K. Honda, Nature (London) 277 (1979), 637.

[18] M. Mehrvar, W. A. Anderson, and M. Moo-Young, International Journal of Photoenergy 2 (2) (2000), 67. 


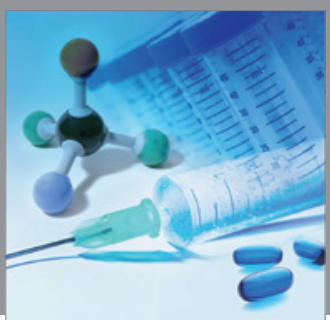

International Journal of

Medicinal Chemistry

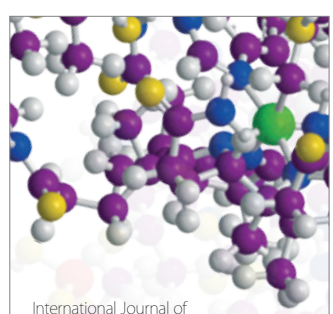

Carbohydrate Chemistry

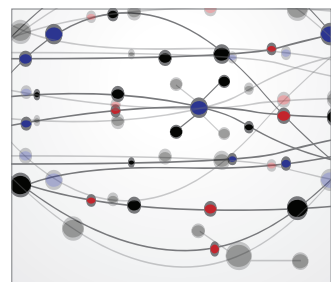

The Scientific World Journal
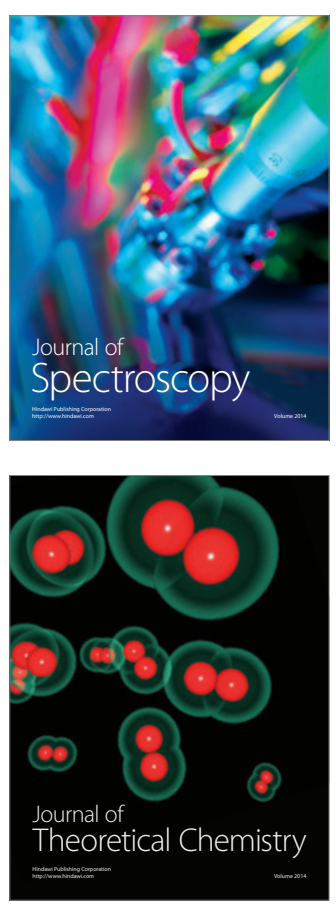
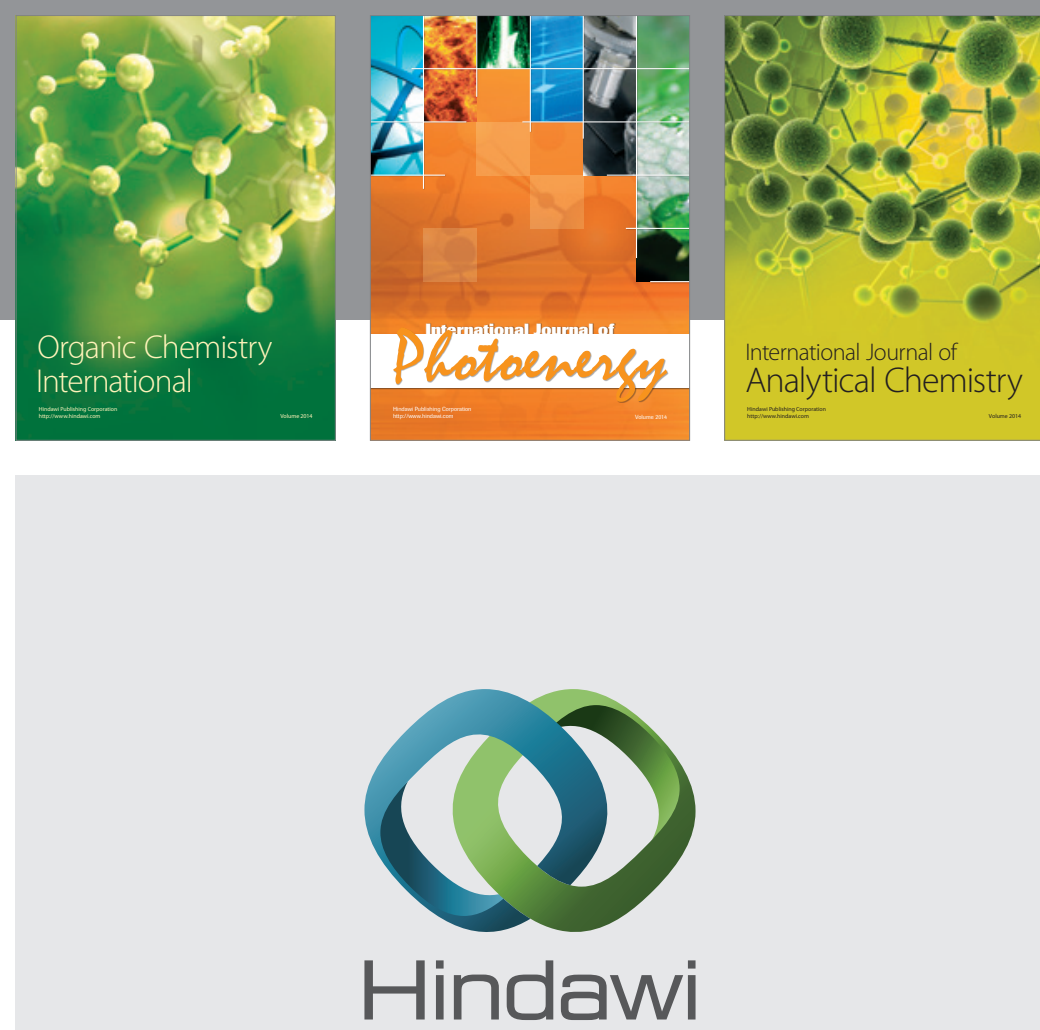

Submit your manuscripts at

http://www.hindawi.com
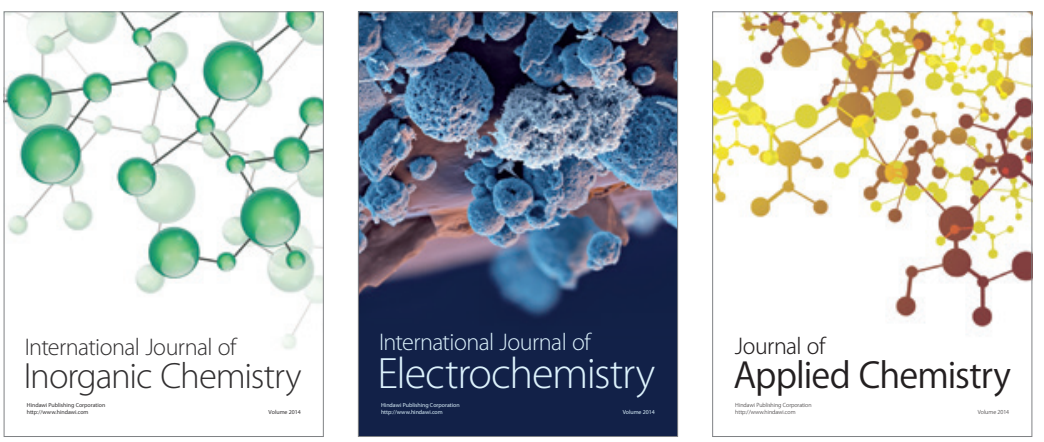

Journal of

Applied Chemistry
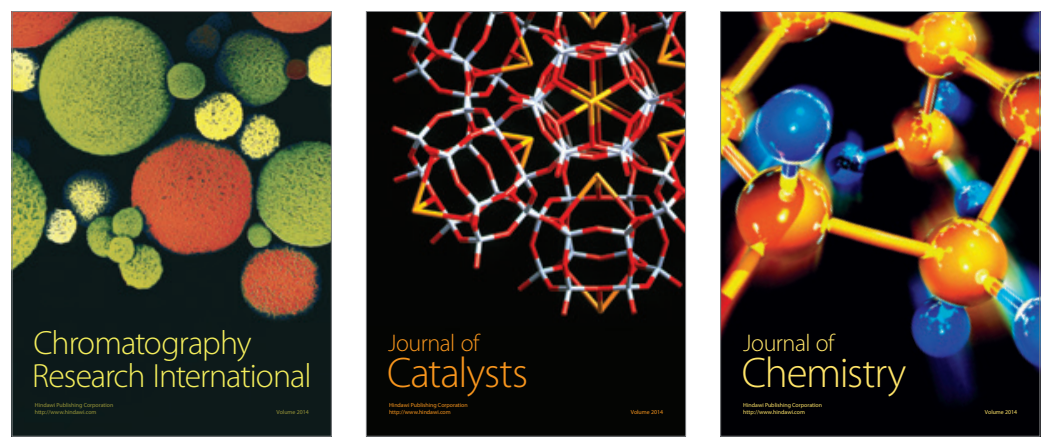
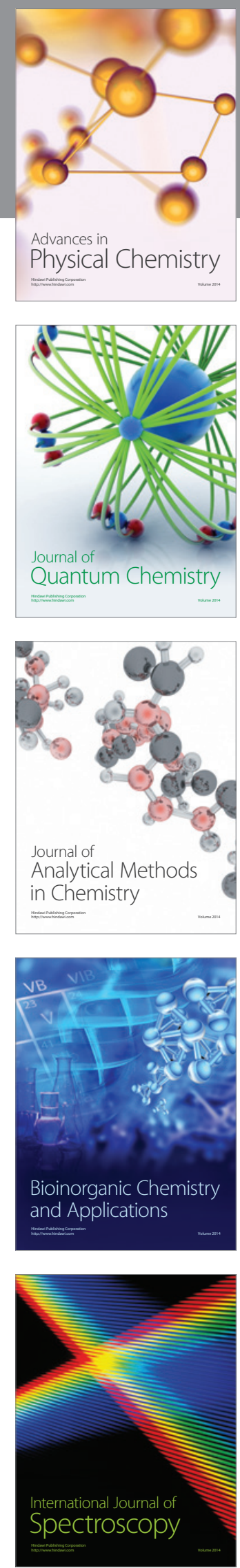